\title{
A method of managing cervicomediastinal tracheal strictures
}

\author{
NATALINO GUERNELLI, ROBERTO VECCHI, ANTONIO BRICCOLI, AND \\ ROMANO B BRAGAGLIA
}

From the Clinica Chirurgica II, University of Bologna, Bologna, Italy

Guernelli, N, Vecchi, R, Briccoli, A, and Bragaglia, R B (1978). Thorax, 33, 508-510. A method of managing cervicomediastinal tracheal strictures. We describe our experience in managing two cases of long tracheal strictures and a method of treating extensive lesions.

In our experience in tracheal surgery we have observed 14 strictures, nine of which followed tracheostomy. Two strictures were cervicomediastinal, with dense scarring just distal to the vocal cords. To treat these two strictures we used a multiple-stage technique.

\section{Stage I}

The stricture (which started just under the vocal cords and terminated in the upper half of the mediastinal trachea) was approached through a sternotomy and longitudinal cervical incision. The mediastinal stricture and the anterior and lateral walls of the strictured laryngocervical segment were resected, conserving the pars membranacea (fig 1). The pars membranacea is usually free of scarring since the tracheostomy and the tube mainly damage the anterior and lateral walls of the trachea. Careful and accurate dissection of the great vessels, bronchi, and trachea allowed the remaining mediastinal trachea to advance to the level of the suprasternal notch so that its cartilaginous portion could be sutured to the skin. The pars membranacea of the cervical segment was then sutured to the pars membranacea of the advanced mediastinal segment with 00 chromic catgut. The lateral margins were sutured to the skin

Fig 1 Stage I. (A) Long cervicomediastinal stenosis. (B) Resection of stenosis and of anterior and lateral walls of cervical trachea conserving pars membranacea. (C) Suture between cervical and mediastinal membranous portions (pars membranacea) and suture of cartilage of mediastinal segment to skin at suprasternal notch level. (D) Lateral view. (E)

Lateral margins of pars membranacea are sutured to skin of neck to form groove-like tracheostomy.

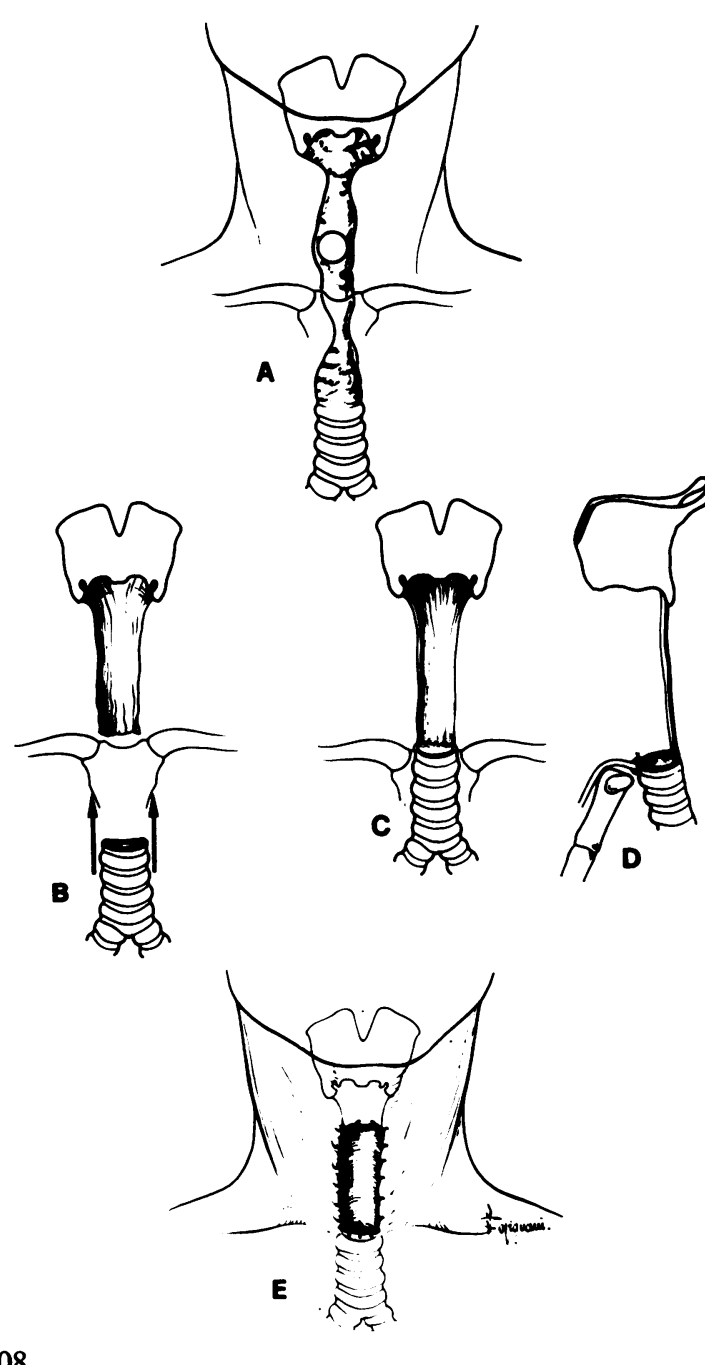



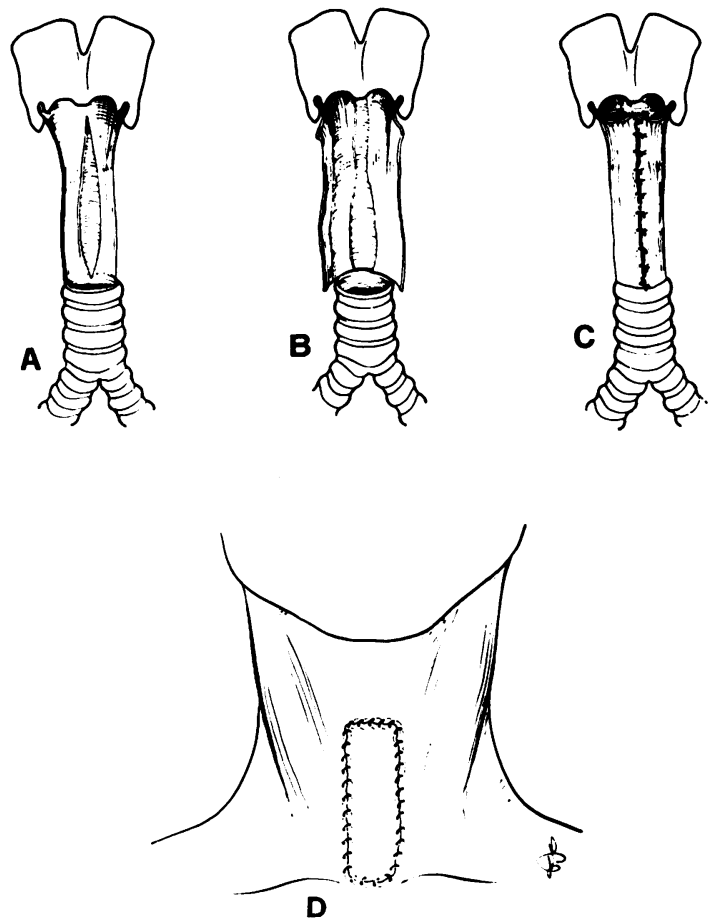

Fig 2 Stage II. (A) Incision through mucosa of posterior wall. $(B)$ Anterolateral displacement of two leaflets. (C) Suture of leaflets in midline. (D) Final result.

of the neck so as to form a long groove-like tracheostomy. Thirty days later stage II was performed.

\section{Stage II (fig 2)}

A long incision was made through the mucosa of the posterior wall. The mucosa was dissected free from the underlying tissues, and the leaflets thus formed were gently pulled laterally and anteriorly until they reached the midline. These leaflets, sutured together in the midline, formed the mucosa of the lateral and anterior walls of the trachea. The "new" anterior wall was reinforced by a skin flap.

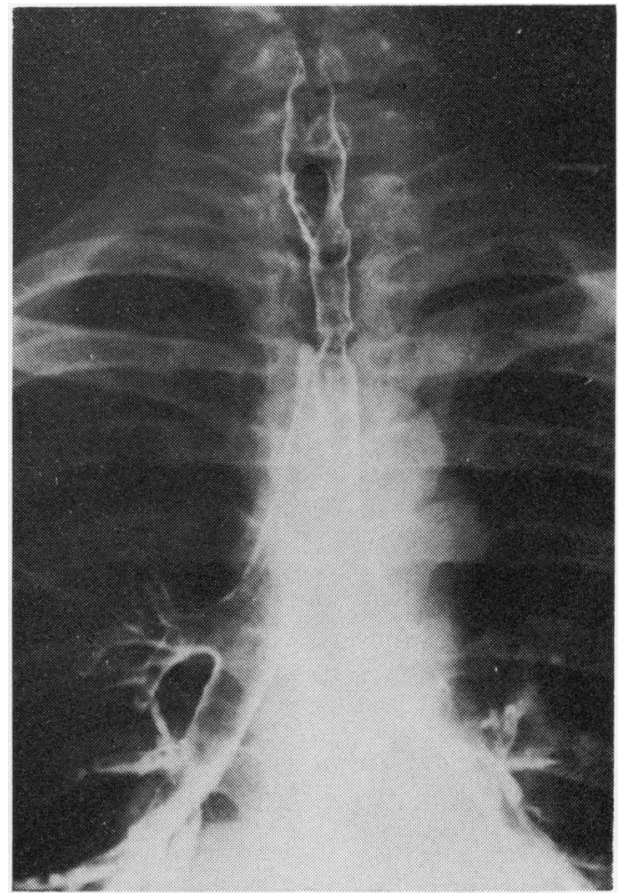

Fig 3 Tracheogram (case 1) showing extent of stricture.

\section{Results}

Both patients were referred from other hospitals, after an emergency high cervical tracheostomy had stenosed (figs 3 and 4), and both were operated on using this method. Case 1 died of severe gastrointestinal haemorrhage seven days after undergoing stage $I$; case 2 is alive and well. Tracheography performed four years after operation (fig 5) shows an adequate anastomotic lumen.

Requests for reprints to: $\operatorname{Dr} \mathrm{R}$ Bragaglia, Clinica Chirurgica II, University of Bologna, Bologna, Italy. 


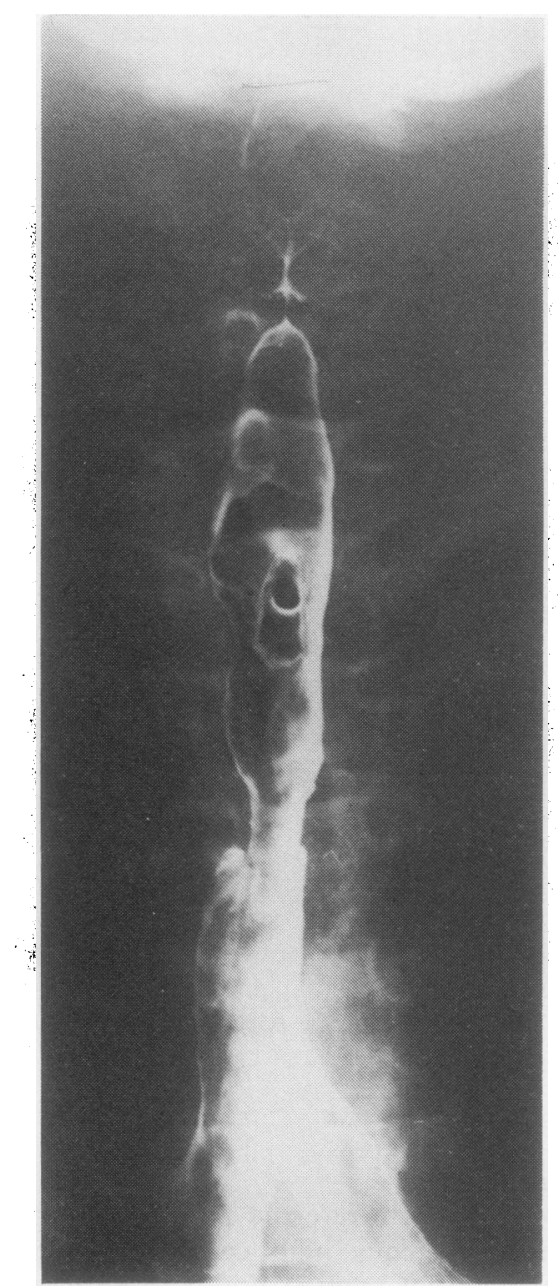

Fig 4 Tracheogram (case 2) showing extent of stricture.

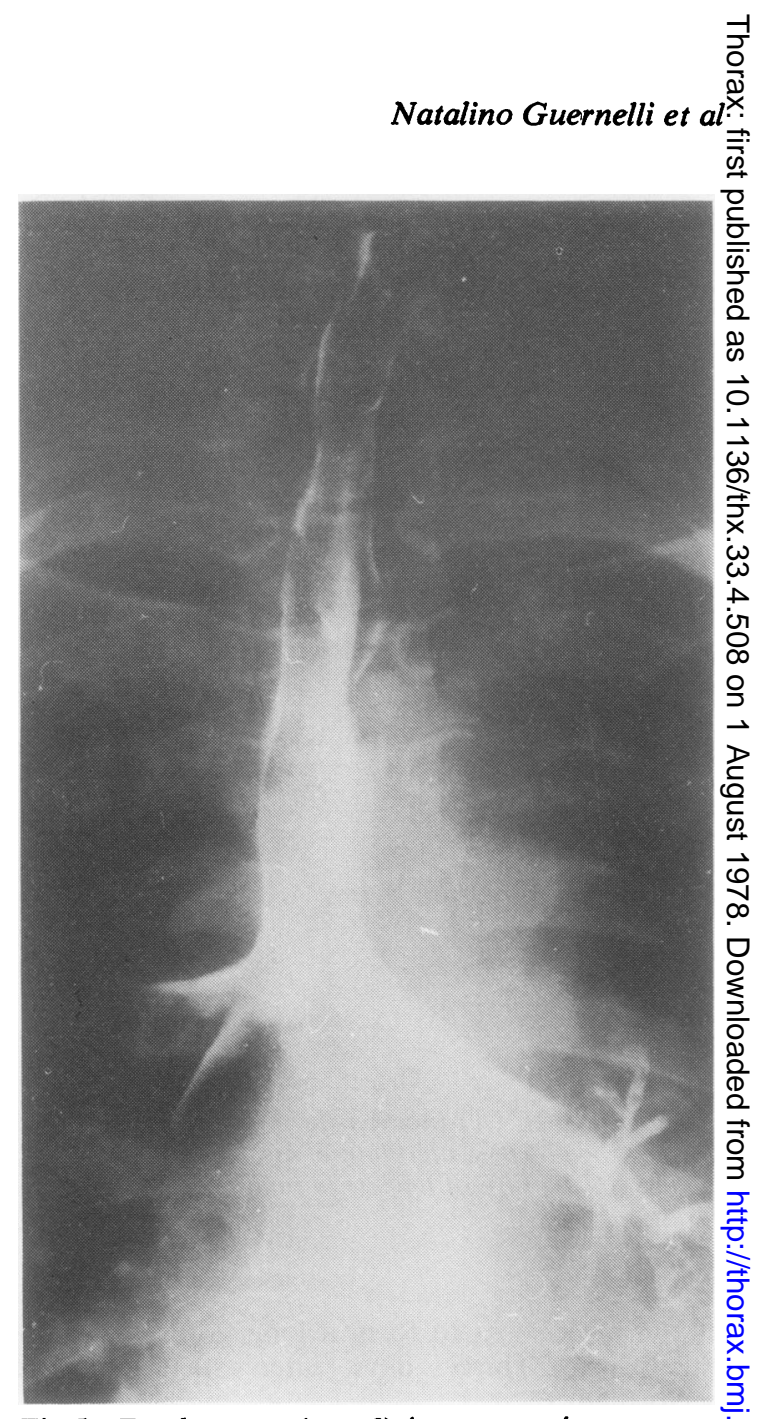

Fig 5 Tracheogram (case 2) four years after operation. Anastomosis at level of suprasternal notch shows adequate diameter. 